\title{
Pelatihan Manajemen Usaha Pengolahan Sabut Kelapa berbasis Bumdes di Desa Manunggal Makmur
}

\author{
Rike Setiawati $^{1}$, Jamal $^{2}$, Zulfina Adriani ${ }^{3}$, Erida $^{4}$, Besse Wediawati ${ }^{5 *}$ \\ 1,2,3,4,5) Fakultas Ekonomi dan Bisnis, Universitas Jambi, Jl. Raya Jambi - Muara Bulian KM. 15, \\ Muaro Jambi, Jambi
}

\begin{abstract}
This activity aims to provide a solution to the problem of coconut coir waste and the problem of BUMDES in the Manunggal Makmur Village which does not yet have a main economic activity to drive the village economy through training in management of coconut coir processing business. This service partner consists of the Management of the Bumdes Manunggal Jaya, the village administrator and the Youth Cadre, which is as many as 15 people. The training method used participatory training that involves participants in every stage of training, from pre-training to the training evaluation stage (Participant Learning Center/PLC and Project Based Learning). The material provided includes organizational management and financial management, production management and export-oriented marketing management. The output achieved from this activity is an increase in the knowledge, understanding and skills of participants in managing a coconut coir processing business. This business is expected to be the main activity of Bumdes in managing the local potential of the village, driving the economy of rural communities who are generally coconut farmers and increasing village original income.
\end{abstract}

Keywords: BUMDES, Business Management, Local Potential

\begin{abstract}
Abstrak
Kegiatan pengabdian ini bertujuan memberikan solusi atas persoalan limbah sabut kelapa dan persoalan BUMDES di Desa Manunggal Makmur yang belum memiliki aktivitas ekonomi utama untuk menggerakkan perekonomian desa melalui pelatihan manajemen usaha pengolahan sabut kelapa. Mitra pengabdian ini terdiri dari Pengurus Bumdes, Perangkat Desa serta Pemuda Kader desa sebanyak 15 orang. Metode pelatihan menggunakan pelatihan partisipatif yang melibatkan peserta dalam setiap tahapan pelatihan mulai dari pra pelatihan hingga tahapan evaluasi pelatihan (Participant Learning Center/PLC dan Project Based Learning). Materi yang diberikan meliputi manajemen organisasi dan manajemen keuangan, manajemen produksi dan manajemen pemasaran orientasi ekspor. Luaran yang dicapai dari kegiatan ini adalah meningkatnya pengetahuan, pemahaman dan keterampilan peserta dalam mengelola usaha pengolahan sabut kelapa. Usaha ini diharapkan menjadi aktivitas utama Bumdes mengelola potensi lokal desa, menggerakkan perekonomian masyarakat desa yang umumnya petani kelapa serta dapat meningkatkan pendapatan asli desa.
\end{abstract}

Kata kunci: BUMDES, Manajemen usaha, Potensi Lokal.

\footnotetext{
* Penulis korespondensi

Email: widya_anwary@yahoo.com
} 


\section{Pendahuluan}

Desa Manunggal Makmur merupakan salah satu desa yang berada di Kecamatan Kuala Jambi, Kabupaten Tanjung Jabung Timur. Desa ini memiliki Bumdesa Manunggal Jaya yang didirikan pada tahun 2016 sebagai perwujudan dari terbitnya UU Desa no.6 tahun 2014. Namun demikian, karena masalah pendanaan, Bumdes ini baru aktif pada tahun 2018. Pada tahun 2017, Bumdesa ini mendapat penyertaan dana desa. Hingga saat ini telah berjalan 2 (dua) unit usaha yaitu warung desa dan Usaha Layanan WIFI. Namun demikian, usaha ini belum dapat memberikan kontribusi yang berarti bagi peningkatan perekonomian dan kesejahteraan masyarakat desa.

Pengurus bumdes serta tokoh masyarakat desa sangat berkeinginan membangun Bumdes sebagai institusi yang dapat meningkatkan Pendapatan Asli desa serta menjadi payung bagi meningkatnya aktivitas ekonomi warga desa. Salah satu cita-citanya adalah mengangkat potensi lokal desa yaitu sebagai penghasil kelapa dalam, dimana salah satu bagian yang terbuang adalah sabut kelapa. selama ini sabut menjadi limbah serta sampah yang menumpuk baik di kebun/atau langkaw yang menimbulkan pemandangan tidak indah dan menimbulkan masalah kesehatan karena menjadi tempat bersarangnya nyamuk atau binatang lainnya. Sabut juga seringkali dibakar oleh warga desa bahkan dibuang ke sungai sehingga terkadang menimbulkan masalah pendangkalan sungai. Selain itu, didasarkan realitas bahwa tingkat kehidupan petani kelapa di desa masih jauh tertinggal bahkan seringkali mengalami kesulitan ekonomi terutama pada masa- masa paceklik saat harga kelapa bulat atau kopra mengalami penurunan. Hal ini disebabkan karena umumnya petani masih berfokus pada menjual kelapa dalam bentuk bulat, atau dalam bentuk kopra (daging kelapa kering). Sementara seperti air dan sabut umumnya terbuang tidak diolah.

Belajar dari pengalaman-pengalaman praktek terbaik (best practices) di desa inovasi, bahwa nilai tambah (value added) pada komoditi pertanian dapat meningkatkan pendapatan masyarakat (Palupi, Alamsyah, Nainggolan, 2017). Salah satu upaya untuk meningkatkan nilai tambah sabut kelapa adalah melalui pengolahan sabut kelapa menjadi sejumlah produk turunan yang bernilai tinggi kualitas ekspor seperti produk cocofiber dan cocopeat. Namun, karena keterbatasan pengetahuan pengurus Bumdes mengenai pengelolaan usaha sabut kelapa ini menjadikan potensi lokal ini belum dapat terealisasi.

Potensi Sabut Kelapa di Desa manunggal makmur cukup besar. Profil desa (2019) menunjukkan bahwa desa ini didominasi oleh perkebunan kelapa dengan total sekitar 74\% dibanding komoditi pertanian lainnya seperti kelapa sawit, pinang, karet dan kopi serta tanaman padi. Selain itu, profesi petani kelapa merupakan profesi dominan (75\%) dibanding profesi lainnya seperti nelayan, peternak, pedagang dan profesi lain. Saat musim paceklik, terkadang harga jual 1 butir kelapa dapat mencapai harga terendah tidak sampai Rp. 1.000, sehingga banyak petani kelapa yang tidak mau mengerjakan kebun kelapanya, karena lebih tinggi biaya produksi daripada hasilnya, menjual kebun kelapanya, atau sementara alih profesi menjadi pedagang atau terpaksa ke luar desa untuk mencari pekerjaan lain untuk memenuhi kehidupan keluarganya.

Potensi Bumdes dalam mengangkat usaha pengolahan sabut kelapa sangat tinggi dimana Permintaan pasar internasional terhadap produk olahan sabut kelapa sedemikian tingginya. Salah satu negara importir adalah Negara China yang membutuhkan 10.000 ton per bulan cocofiber. Demikian pula dengan Negara Jepang, Korea Selatan, USA dan Eropa yang setiap tahunnya membutuhkan 24.000 Ton untuk setiap bulannya atau sekitar 288.000 ton/tahun. Sementara produktifitas Negara Indonesia dalam menghasilkan produk olahan sabut kelapa ini masih sangat kecil. Untuk cocopeat dan cocofiber ekspor negara Indonesia baru sekitar 32.400 ton per tahun atau rata-rata 2.700 ton per bulan atau tidak sampai $10 \%$ (suaracyber.com, 23/9/2019). 
Bumdes dapat mengambil peran melalui usaha pengolahan sabut kelapa yang menghasilkan produk bernilai tinggi seperti cocopeat dan cocofiber berorientasi ekspor. Bumdes dapat menjalankan perannya sebagai institusi desa yang dapat mendorong bangkitnya aktivitas ekonomi warga desa dan pilar bagi majunya ekonomi desa. Keinginan pengurus Bumdes dan perangkat desa sejalan dengan hadirnya Tim pengabdian yang dapat memberikan pelatihan manajemen usaha dan memfasilitasi Bumdes terhubung dengan Asosiasi Indsutri Sabut Kelapa Indonesia yang dapat merealisasikan pemasaran produk olahan sabut kelapa berorientasi ekspor.

Dengan demikian tujuan dari kegiatan pengabdian ini adalah memberikan pelatihan manajemen usaha pengolahan sabut kelapa bagi pengurus desa sehingga dapat merealisasikan usaha unggulan berbasis potensi local desa sebagai aktivitas utama Bumdes. Pada gilirannya aktivitas ini dapat menyerap tenaga kerja di desa, menggerakkan perekonomian warga desa, menguatkan peran Kelembagaan Bumdes dan berkontribusi bagi desa-desa sekitar di Kecamatan Kuala Jambi khususnya dan Tanjab Timur yang pada umumnya memiliki potensi dominan pertanian kelapa dalam.

\section{Metode Pengabdian}

\section{Metode Pelatihan}

Kegiatan pelatihan manajemen usaha bagi pengurus Bumdes dan perangkat Desa menerapkan metode pelatihan partisipatif yang melibatkan peserta pelatihan dalam setiap tahapan pelatihan mulai dari pra pelatihan hingga tahapan evaluasi pelatihan (Participant Learning Center/PLC). Pada tahapan awal, mitra PPM dan Tim pengabdian mendiskusikan kebutuhan pengurus Bumdes terkait materi, metode, jadwal seta lokasi pelatihan. Tehnik Bottom up ini dilakukan agar kegiatan pengabdian benar-beanr dilakukan berdasarkan kebutuhan Mitra sebagai solusi bagi masalah yang dihadapi.

\section{Materi Pelatihan}

Untuk materi pelatihan dilakukan mealui ceramah, diskusi dan demonstrasi. Sementara untuk materi manajemen keuangan dan pemasaran dilakukan metode project based learning, dimana peserta pelatihan menyelesaikan tugas yang diberi berupa laporan arus kas serta strategi pemasaran ekspor yang dilatih oleh Tim Ahli dari Asosiasi Industri Sabut Kelapa Indonsia (AISKI).

\section{Peserta pelatihan}

Peserta pelatihan ini adalah pengurus Bumdes, perangkat Desa serta kader desa yang terdiri dari anak anak muda desa yang dipilih oleh kades karena dinilai memiliki semangat kewirausahaan dan dapat mewujudkan usaha pengolahan sabut kelapa di desa. Total peserta pealtihan ini sebanyak 15 orang.

\section{Hasil dan Pembahasan}

Pelatihan Manajemen usaha bagi pengurus Bumdes, perangkat Desa serta kader desa Manunggal Makmur dilaksanakan selama 2 kali pertemuan, dimana sebelumnya telah dilakukan kordinasi dan konsultasi dengan kepala desa dan pengurus desa terkait implementasi kegiatan.

Secara rinci pelaksanaan kegiatan pelatihan disajikan pada tabel berikut: 
Tabel 1. Kegiatan, Tujuan, Metode serta bahan dan Alat

\begin{tabular}{|c|c|c|c|c|}
\hline$\overline{\text { No }}$ & $\begin{array}{l}\text { Kegiatan/Jumlah } \\
\text { peserta }\end{array}$ & Tujuan Kegiatan & Metode & Waktu, Lokasi \\
\hline 1 & $\begin{array}{l}\text { KontrakBelajar } \\
\text { (kades dan } \\
\text { pengurus Bumdes, } \\
3 \text { orang) }\end{array}$ & $\begin{array}{l}\text { Membangun kesepahaman } \\
\text { mengenai tujuan dan } \\
\text { pelaksanaan kegiatan } \\
\text { pengabdian }\end{array}$ & $\begin{array}{l}\text { - Ceramah, } \\
\text { - diskusi, } \\
\text { - curah gagasan. }\end{array}$ & $\begin{array}{l}2 \times 45 \text { menit } \\
\text { Balai Desa } \\
\text { Manunggal } \\
\text { Makmur }\end{array}$ \\
\hline 2 & $\begin{array}{l}\text { Pelatihan } \\
\text { ManajemenUsaha } \\
\text { dari aspek } \\
\text { Organisasi dan } \\
\text { keuangan } \\
\text { (15 orang) }\end{array}$ & $\begin{array}{l}\text { Pengurus Bumdesa memahami } \\
\text { manajemen usaha pengolahan } \\
\text { sabut kelapa, yaitu meliputi } \\
\text { Aspek Organisasi dan } \\
\text { keuangan. } \\
\text { Pengurus bumdes paham dan } \\
\text { mampu membuat laporan arus } \\
\text { kas }\end{array}$ & $\begin{array}{l}\text { Ceramah, } \\
\text { Demonstrasi } \\
\text { Project based } \\
\text { learning }\end{array}$ & $\begin{array}{l}1 \times 45 \text { Menit Untuk } \\
\text { aspek Organisasi } \\
2 \times 45 \text { Menit untuk } \\
\text { aspek keuangan }\end{array}$ \\
\hline 3 & $\begin{array}{l}\text { Pelatihan Aspek } \\
\text { produksi } \\
\text { (2 orang) }\end{array}$ & $\begin{array}{l}\text { Kader desa terpilih mengikuti } \\
\text { pelatihan produksi pengolahan } \\
\text { sabut kelapa, memahami tehnik } \\
\text { produksi olah sabut kelapa } \\
\text { menjadi produk cocopeat dan } \\
\text { cocofiber }\end{array}$ & $\begin{array}{l}\text { Ceramah, Praktek } \\
\text { langsung. }\end{array}$ & $\begin{array}{l}7 \text { hari di Pabrik } \\
\text { pengolahan sabut } \\
\text { kelapa di desa } \\
\text { tanjung bintang, } \\
\text { Lampung Selatan. }\end{array}$ \\
\hline 4 & $\begin{array}{l}\text { Pelatihan } \\
\text { Manajemen } \\
\text { Pemasaran } \\
\text { (3 orang Pengurus } \\
\text { bumdes dan } 2 \\
\text { orang Kader Desa) }\end{array}$ & $\begin{array}{l}\text { Pengurus Bumdesa memahami } \\
\text { manajemen pemasaran dan } \\
\text { mampu mendesain strategi } \\
\text { pemasaran } \\
\text { Ekspor bagi produk olahan } \\
\text { sabut kelapa. }\end{array}$ & $\begin{array}{l}\text { Ceramah, } \\
\text { Demonstrasi } \\
\text { Project Based } \\
\text { Learning } \\
(2 \times 45)\end{array}$ & $\begin{array}{l}2 \times 45 \text { Menit } \\
\text { Balai Desa } \\
\text { Manunggal Makmur } \\
\text { Bagi Penguru } \\
\text { Bumdes } \\
3 \text { hari bagi kader } \\
\text { desa di Pabrik } \\
\text { Pengolahan sabut } \\
\text { Kelapa Desa Natar } \\
\text { Lampung Selatan. }\end{array}$ \\
\hline
\end{tabular}

Segenap rangkaian kegiatan Pelatihan ini diikuti dengan semangat dan penuh keseriusan oleh peserta pelatihan yang terdiri dari pengurus bumdes, perangkat desa serta kader desa. Hal ini dikarenakan, materi yang diberikan merupakan materi yang sangat dibutuhkan oleh peserta pelatihan. Kegiatan dilaksanakan di dua tempat, yaitu di Balai desa manunggal makmur untuk materi kontrak belajar, manajemen organisasi dan keuangan.

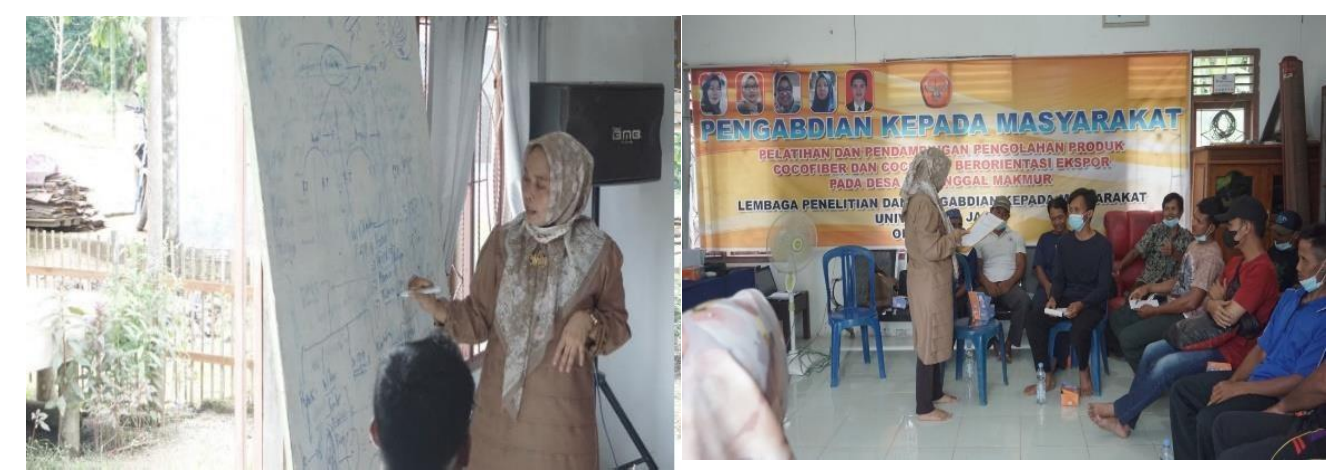

Gambar 1 : Pelatihan Manajemen Organisasi dan Keuangan bagi Pengurus Bumdes

Sementara untuk materi manajemen produk pengolahan sabut kelapa dan materi pemasaran produk berorientasi ekspor dilakukan di Lampung. Tim Pengabdian memfasilitasi 2 orang pemuda kader desa mengikuti pelatihan manajemen produksi pengolahan sabut 
kelapa selama 7 hari ke Sentra pengolahan sabut kelapa di Desa Jati Baru, Tanjung Bintang, Kota Lampung Selatan.
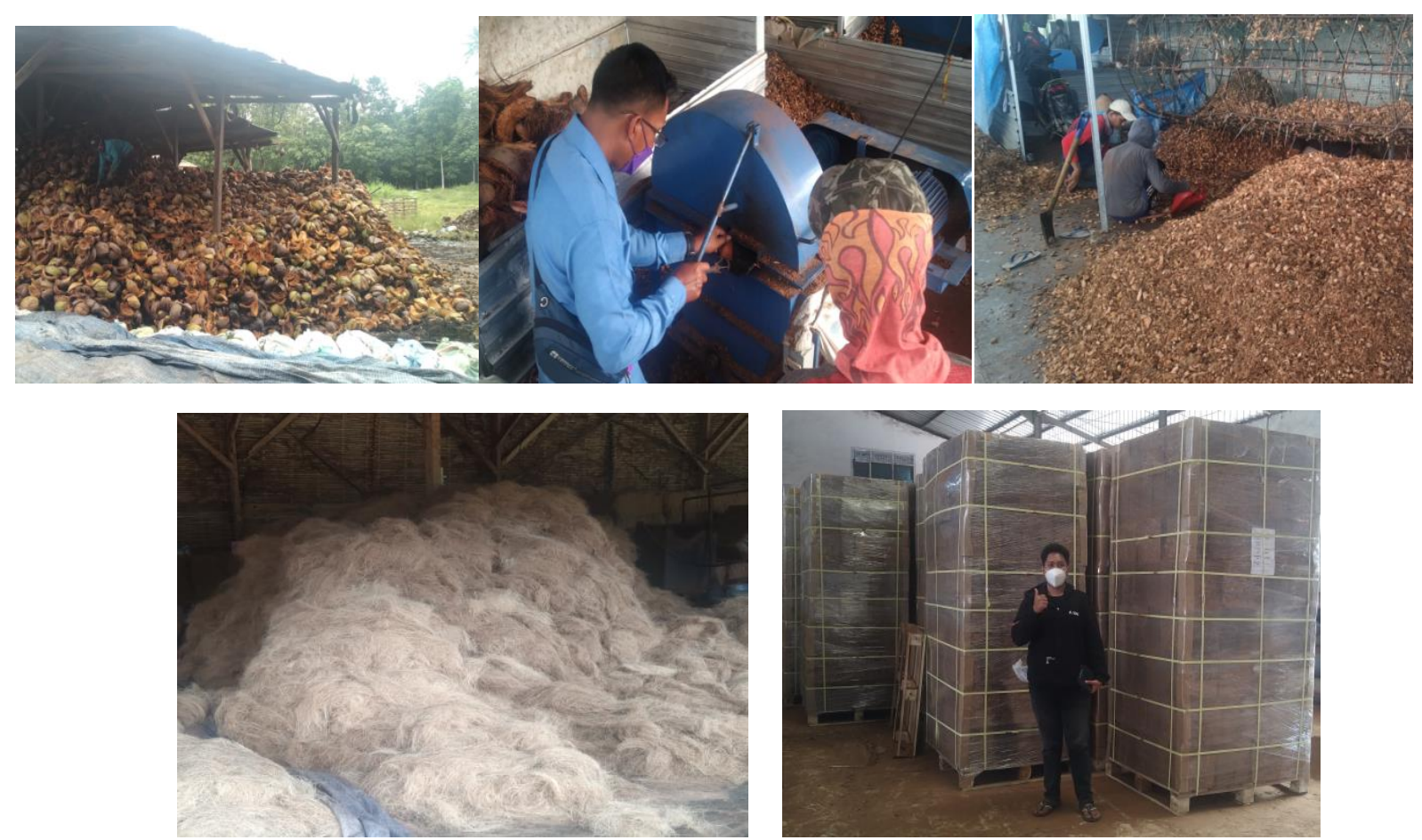

Gambar 2. Pelatihan Manajemen Produksi di Sentra Pengolahan Sabut Kelapa Tanjung Bintang, Lampung.

Demikian pula untuk materi manajemen pemasaran orientasi ekspor, 2 orang pemuda kader desa mengikuti pelatihan ini di pabrik sabut kelapa PT. Mahligasi Cocofiber selama 3 hari di desa Natar Kota Lampung Selatan. Selanjutnya, kedua kader pemuda desa ini akan mentransfer pengetahuan dan keterampilannya kepada pengurus Bumdes dan segenap warga desa menuju pembangunan pabrik pengolahan sabut kelapa di desa Manunggal makmur.

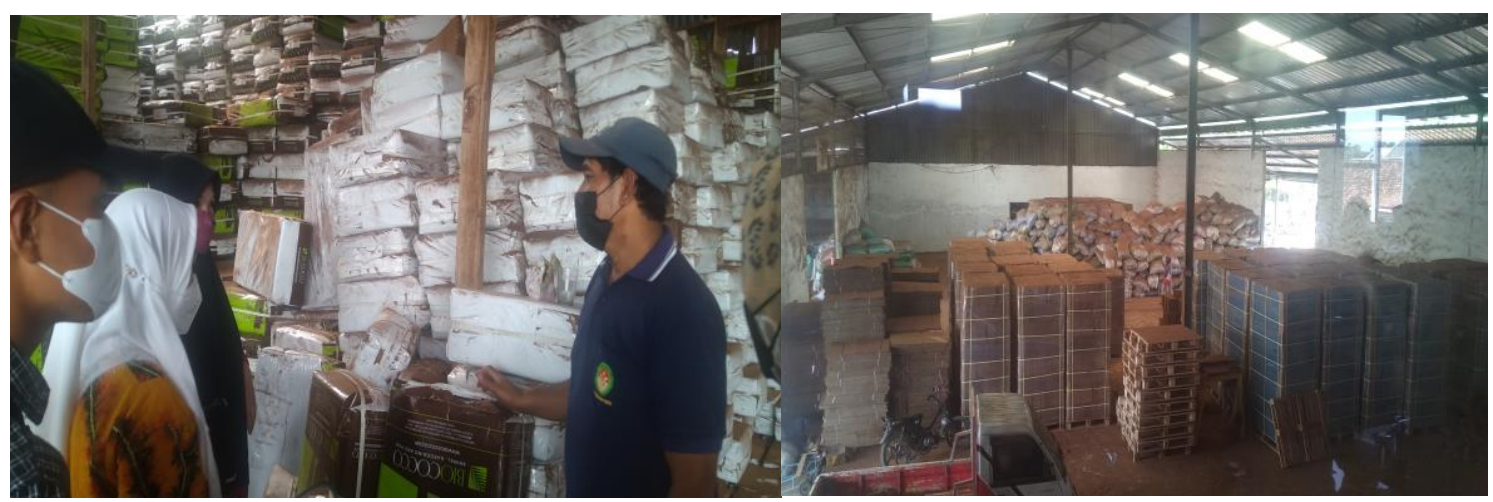

Gambar 3. Pelatihan Manajemen Pemasaran di Pabrik Pengolahan Sabut Kelapa, Natar, Lampung Selatan. 


\section{Kesimpulan dan Saran}

\section{Kesimpulan}

Pelaksanaan kegiatan pelatihan manajemen usaha telah dilaksanakan melalui sejumlah tahapan sebagaimana yang telah direncanakan. Tahapan kegiatan terdiri dari 4 kegiatan yaitu kontrak belajar, pelatihan organisasi dan manajemen keuangan, pelatihan manajemen produksi dan manajemen pemasaran. Keberhasilan kegiatan pelatihan ini ditandai dengan antusias yang tinggi dari kepala desa, pengurus Bumdes serta pemuda Kader Desa dalam mengikuti semua tahapan kegiatan pengabdian. Bahkan menghasilkan kesepakatan dan komitmen bersama untuk segera mengimplementasikan terciptanya sentra produksi pengolahan sabut kelapa sebagai aktivitas ekonomi utama bagi Bumdes untuk menggerakkan perekonomian warga desa yang dapat meningkatkan penghasilan masyarakat desa serta pendapatan asli desa (PADes).

\section{Saran}

Berdasarkan hasil pengabdian, untuk mewujudkan rencana mendirikan sentra pengolahan sabut kelapa di desa Manunggal Makmur yang dikelola oleh Bumdes, maka disarankan : 1) Desa Manunggal Makmur menjadi desa Binaan Tim Pengabdian PPM Universitas Jambi serta menjalin kerjasama kemitraan dengan Asosiasi Industri sabut Kelapa sehingga memiliki Tim Ahli dan Tim Teknis untuk mendampingi usaha pengolahan sabut Kelapa yang dikelola oleh Bumdes; 2) Sentra pengolahan sabut kelapa berpotensi melibatkan desa-desa sekitar yang juga didominasi oleh perkebunan kelapa, sehingga disarankan bagi pengurus bumdes dapat berkoordinasi dengan perangkat desa/pengurus bumdes lainnya agar dapat membangun kemitraan pemasok (supplier) sabut kelapa bagi pabrik yang akan didirikan.

\section{Daftar Pustaka}

Palupi, Kartika Retno And Alamsyah, Zulkifli And Nainggolan, Saidin Analisis Nilai Tambah Kelapa Dalam Dan Pemasaran Kopra Di Kecamatan Nipah Panjang Kabupaten Tanjung Jabung Timur. Fakultas Pertanian.

Fitriani, D. (2019). Analisis Pengaruh Faktor Internal Terhadap Pendapatan Petani Kelapa (Studi Kasus Di Desa Manunggal Makmur, Kecamatan Kuala Jambi) (UIN SulthanThaha Saifuddin Jambi). Retrieved From Http://Repository.Uinjambi.Ac.Id/1754/1/Ses 141276_Dini Fitriani_Ekonomi Syariah - Dini Fitriani.Pdf

Indahyani, T. (2011). Pada Perencanaan Interior Dan Furniture Yang Berdampak Pada Pemberdayaan Masyarakat Miskin. Humaniora, 2(1), 15-23.

Tobing, S. (2020). Analisis Usaha Agroindustri Kerajinan Keset Sabut KelapaAnalysis Of Coconut Fiber Doormat Agroindustry Business. 2(April), 31-49.

https://www.kompasiana.com/nugrahajs/56f0e2a2737e617b048b456a/cara- mengolah-sabutkelapa

https://suarasiber.com/2019/09/pasar-internasional-butuh-sabut-kelapa-408-ribu-ton-per-tahun/

(C) 2021 oleh penulis. Pemegang Lisensi JPM, Indonesia. Artikel ini merupakan artikel akses terbuka yang didistribusikan di bawah syarat dan ketentuan Lisensi Atribusi Creative Commons (CC BY-SA) 